\title{
Maxims in Novel "The Fault in Our Stars" by John Green: Pragmatics Approach
}

\author{
Sasmi Saragih ${ }^{1}$, Mhd. Johan ${ }^{2}$ \\ pb161210099@upbatam.ac.id1 1 , Mhd.Johan@puterabatam.ac.id ${ }^{2}$ \\ 1, 2.Universitas Putera Batam (UPB), Batam, Indonesia
}

Received: 17 June 2020 Accepted: 30 June 2020

DOI: 10.24256/ideas.v8i1.1401

\begin{abstract}
This research aimed at analyzing the types of maxims of the cooperative principle that were used in the novel entitled The Fault in Our Stars. The data source of data was a novel entitled The Fault in Our Stars that fulfilled cooperative principle based on four maxims of cooperative principles: Maxim of quantity, maxim of quality, maxim of relation, and maxim of manner. Theory that the researcher used in this research was theory of Grice. In this research, a descriptive qualitative method was applied to answer the research questions. The observational method and non-participatory technique were applied by the researcher in collecting the data. In analyzing the data the researcher used pragmatic identity method based on the theory of Sudaryanto. The results showed that the level of cooperative principle was mostly used in the novel. The researcher found 30 data related to cooperative principle. The maxims of quantity have 15 data, 3 for maxim of quality, 10 for maxim of relation and maxim of manner has only 2 data.
\end{abstract}

Keywords: Cooperative Principle, Maxims, Pragmatics 


\section{Introduction}

In daily life, people cannot separate from communication in society. People do conversation by using language. Language is an important thing in our life. It has a big effect on the human to interact with another. The example of language used in life such as thinking, communicating, expressing feeling and another. The way people give a message or what people thought is using language. When people do conversation, the hearer usually tries to understand the meaning of the words and what the speaker or writer wants to say. It means that both speaker and listener must be able to deliver their intended message clearly so that both of them can understand each other. The study on intended speaker meaning in context is called pragmatics (Yule, 2005).

Human needs communication to connect with other people. People use language to convey a message such as from a speaker to listener or from writer to reader. By using communication people can show anything with their society and friends. In conversation, there are speaker and hearer. In every conversation, people should make good cooperation with others. They can understand each other utterance and their conversation become smooth and successful by using cooperation. The cooperation in their conversation is called as cooperative principle. According to H. Paul Grice (1975) (as cited in (Betty J. Birner, 2013), the purpose of cooperative principle is to get effective communication as informative as clearly. It has four maxims they are quantity maxim, quality maxim, relation maxim and manner maxim in (Utami, Nugraheni, \& Hardiyanti, 2017). One example of that maxim used in conversation is below:

Mom : Do you want me to carry it in for you?

Hazel : No, It's fine (Green, 2012 Chpt 1 p. 8)

From the example we can see that there is cooperation in this conversation. They used one of maxim above that is maxim of quantity. It can be seen what the meaning of quantity here, only say that for which you have adequate evidence. It can be seen from the answer of the second person "No, it's fine". The second person gives a short answer that the first person needs even though actually she/he can give more information or more answer about that.

This research focused on the analysis of four maxims. The four maxims were analyzed in this research to get the speaker means in the utterance. In understand the intended meaning of the speaker, it also needs the context of the conversation. In normal communication, it can be assumed that the speaker articulates the utterance to communicate something that will be communicated. In this case, the speaker always tries their utterance will be relevant with the context, clear or easy to understand so it will not waste the time to understand the sentence. The four maxims are important to learn to improve our knowledge. All of them are very useful for us to learn to know how the way we speak to another person. So, we can speak in good conversations with every people.

To support this study, the researcher shows two journals as the previous research that has the same topic with this research. Laila (2019) analyze about 
cooperative principles in the 2019 Indonesian Presidential Debate. This research aimed to analyze the types of maxims of the cooperative principle that were used and also violated in the 2019 Indonesian presidential debate used Grice's maxim analysis. Sapalakkai (2018) described the cooperative principle used by Chris Gardner in "The Pursuit of Happyness" movie. This study is to find out what maxims are used by Chris Gardner, what maxims are flouted by Chris, and what implicature can be interpreted by flouting the maxims in the business conversation in The Pursuit of Happiness movie.

The researcher interested in discussing maxim in this novel is because there are so many utterances that contain maxims in this novel. There is so many conversations in which maxim exists. This research aims to describe the types of maxims in novel "The Fault in Our Stars. The researcher limited the problem only for the types of maxims in novel "The Fault in Our Stars. The researcher focused on the conversation in the novel to get the data.

According to Yule (2005), pragmatics can be defined as the study of what speakers mean or 'speaker meaning'. Pragmatics is the study of utterances that said by the speaker and interpreted by the hearer. Pragmatics also can be defined as the study of contextual meaning. It related to how speaker organizes what he or she wants to say. Communication clearly depends on not only recognizing the meaning of words in an utterance but recognizing what speakers mean by their utterances. Pragmatics is a subfield of linguistics that studies the ways in which context contributes to meaning.

Hickey ( as cited in Sembiring \& Ambalegin, 2019) stated that pragmatics is the language use in interpersonal communication. It is concerned with the choices made by speakers and the options and constraints which apply in social interaction.

Grice's formulation of the Cooperative Principle is rather more detailed: The Cooperative Principle: Make your conversational contribution such as is required, at the stage at which it occurs, by the accepted purpose or direction of the talk exchange in which you are engaged (Grice, 1975). The Cooperative Principle consists of four "maxims," each of which covers one aspect of linguistic interaction and describes what is expected of a cooperative speaker with respect to that maxim. The maxims are maxim of quantity: say enough, but don't say too much, maxim of quality: Say only what you have reason to believe is true, maxim of relation: Say only what is relevant and maxim of manner: Be brief, clear, and unambiguous (Betty J. Birner, 2013).

The maxim of quantity Grice's formulation has two parts. First, make your contribution as informative as is required for the current purposes of the exchange and the second do not make your contribution more informative than is required.

Example:

A: Where do we have Pragmatics classes tonight?

B: In W203 room!

From the example, we can see what the meaning of the quantity here. It can be seen from the answer of the second person. The second person gives a short 
answer that the first person needs even though actually she/he can give more information about that.

According to Grice ( as cited in Andy \& Ambalegin, 2019) people had to speak what they believe true and in fact, it could happen. In this maxim, an utterance should be said truly based on what happening in real life. The maxim of quality Grice's formulation is composed of the following two sub-maxims, first do not say what you believe to be false and the second, do not say that for which you lack adequate evidence. This maxim is sometimes paraphrased as "say what is true" or something along those lines, but Grice realized that of course one cannot always (or perhaps ever) be certain of what is true; the best one can do is to say only what one believes to be true.

Example:

A: Do you know where Putera Batam University is?

B: In Jl. Soeprapto Muka Kuning batam.

In this case, the answer of the second person related to the quality. The answer from the second person is required to be original and justified.

The maxim of relation is sometimes called the maxim of relevance because it is composed of only the following two-word dictum: Be relevant. The term "relation" is appropriate for this maxim because it has to do with the relationship between the current utterance and others preceding and following it, and more generally with the relationship between the current utterance and the entire context, both textual and situational that is, both what is occurring in the discourse and the nature of the surroundings in which the discourse is taking place. What is meant by this maxim is that the current utterance must have something to do with the context; it must be related to what has come before it in the discourse and/or what is going on in the situation.

Example:

A: Do you like doing sport?

B: Only Soccer.

From the sentence, we can see where the relation there. It can be seen from the answer of the second person. She/he answers something that relevant to the aim of the question in conversation. Another example is below:

Hazel : Why are you looking at me like that?

Augustus: Because you are beautiful. I enjoy looking at beautiful people, and I decided a while ago not to deny myself the simpler pleasure of existence. (Green, 2012 Chpt 1 p.16)

This data is also example of maxim of relation. In this case, the answer of the second person: "Because you are beautiful. I enjoy looking at beautiful people..." related to the relation. The answer from the second person is relevant to the question of first character.

The maxim of manner as last of Grice's maxims is also ironically the least straightforward. This maxim of manner states several things such as avoid obscurity of expression, avoid ambiguity, be brief (avoid unnecessary prolixity) and the last be 
orderly. Unlike the other three maxims, this one is a bit of a grab bag of sub-maxims that are neither tightly related nor opposing sides of the same coin (as with the submaxims of Quantity). For example, avoiding ambiguity and being brief, while both important to clear communication, are really quite distinct things: It is possible to be long-winded and unambiguous or to make an ambiguous utterance in very few words.

Example:

A: How do you find the nearest post office last night?

B: I call my friends who live around the post office and he hit me up to the post office.

The example explains in a good manner so the information can be understood clearly.

\section{Method}

This research applied a descriptive qualitative research method. The aim was to explain each of the types of cooperative principle that is maxim in the novel entitled The Fault in Our Stars. The data that is the researcher used in this research was taken from the conversation in the novel. The types of maxim were classified based on Grice's theory. To collect data the researcher was applied observational method and non- participatory technique. In analyze the data the researcher used pragmatic identity method and used pragmatic competence in dividing technique. . The basic technique used is the determining element (PUP) technique. The researcher analyzed based on the theory of (Sudaryanto, 2015).

\section{Results an Discussion}

In result analysis, there are 30 utterances of cooperative principle that is maxim. From 30 data that is taken, there are 15 maxims of Quantity, 3 maxims of Quality, 10 maxims of Relation, and only 2 maxims of Manner. The findings of this research can be seen from the table below:

Table 1 Maxim used in novel "The Fault in Our Stars

\begin{tabular}{|c|c|c|}
\hline No & Types of maxim & Amount \\
\hline 1 & Maxim of Quantity & 15 \\
\hline 2 & Maxim of Quality & 3 \\
\hline 3 & Maxim of Relation & 10 \\
\hline 4 & Maxim of Manner & 2 \\
\hline & Total amount of data & 30 \\
\hline
\end{tabular}

\section{Maxim of Quantity}

\section{Data 1}

Mom : Do you want me to carry it in for you? 
Hazel : No, it's fine (Green, 2012 Chpt 1 p.8)

The first datum is an example of maxim of quantity. From the example, it can be seen the meaning of the quantity here. As quantity means only say that for which you have adequate evidence. It can be seen from the answer of the second person "No, it's fine". The second person gives a short answer that the first person needs even though actually she/he can give more information about that.

\section{Data 2}

Patrick : And how are you feeling?

Augustus : Oh, I'm grand (Green, 2012 Chpt 1 p.11)

The second datum is also an example of maxim of quantity. From the example, it can be seen what the meaning of the quantity here, only say that for which you have adequate evidence. It can be seen from the answer of Augustus "Oh, I'm grand". Actually the second person can give the long answer to the question of the first person, but he prefers to give a short answer.

\section{Data 3}

Augustus Dad :How was Isaac's Support Group?

Augustus : It was incredible (Green, 2012 Chpt 2 p.27)

The third datum is also the example of maxim of quantity. From the example, it can be seen what the meaning of the quantity here, only say that for which you have adequate evidence. It can be seen from the answer of Augustus "It was incredible". Actually the second person can give the long answer to the question of the first person, but he prefers to give a short answer.

\section{Data 4}

Kaitlyn : Darling. How are you?

Hazel : I'm good. (Green, 2012 Chpt 3 p.42)

The fourth datum is also example of maxim of quantity. From the example it can be seen the meaning of the quantity here, only say that for which you have adequate evidence. It can be seen from the answer of Hazel "I'm good". Actually the second person can give the long answer of the question of the first person, but he prefers to give a short answer.

\section{Data 5}

Kaitlin :What is new in the Hazelverse?

Hazel :Nothing, really (Green, 2012 Chpt 3 p.42)

The fifth datum is example of maxim of quantity. From the example it can be seen the meaning of the quantity here, only say that for which you have adequate evidence. It can be seen from the answer of Hazel "Nothing, really". Actually the second person can give the long answer of the question of the first person, but he prefers to give a short answer.

\section{Data 6}

Jackie : Thanks for letting me try it

Hazel : No problem. (Green, 2012 Chpt 3 p.47)

The sixth datum is example of maxim of quantity. It can be seen the meaning of 
the quantity here. As quantity means only say that for which you have adequate evidence. It can be seen from the answer of the second person "No problem". The second person gives a short answer that the first person need even though actually she/he can give more information about that.

\section{Data 7}

Augustus : Can you meet us at my house in, say, twenty minutes?

Hazel : Sure

The next datum is an example of maxim of quantity. From the example, it can be seen the meaning of the quantity here. As quantity means only say that for which you have adequate evidence. It can be seen from the answer of the second person "Sure". The second person gives a short answer that the first person needs.

\section{Data 8}

Augustus : Can I carry your, uh, tank?

Hazel : Nah, I'm good. Thanks, though, Mr. Waters

The next datum is an example of maxim of quantity. It can be seen the meaning of the quantity here. As quantity means only say that for which you have adequate evidence. It can be seen from the answer of the second person "Nah, I'm good. Thanks, though, Mr. Waters". The second person gives a short answer that the first person needs even though actually she/he can give more information about that.

\section{Data 9}

Augustus : Feel better?

Isaac : No

The next datum is an example of maxim of quantity. It can be seen the meaning of the quantity here. As quantity means only say that for which you have adequate evidence. It can be seen from the answer of the second person "No". The second person gives a short answer that the first person needs even though actually she/he can give more information about that.

\section{Data 10}

Augustus : Right. You said he is a recluse?

Hazel : Correct

The next datum is an example of maxim of quantity. From the example, it can be seen the meaning of the quantity here. As quantity means only say that for which you have adequate evidence. It can be seen from the answer of the second person "Correct". The second person gives a short answer that the first person needs even though actually she/he can give more information about that.

\section{Data 11}

Hazel :Can I have the email address?

Augustus :Of course

The next datum is an example of maxim of quantity. It can be seen the meaning of the quantity here. As quantity means only say that for which you have adequate evidence. It can be seen from the answer of the second person "Of course". The second person gives a short answer that the first person needs even though actually she/he can give more information about that. 
Data 12

Mother : What's wrong?

Hazel : Nothing

The next datum is an example of maxim of quantity. From the example, it can be seen the meaning of the quantity here. As quantity means only say that for which you have adequate evidence. It can be seen from the answer of the second person "Nothing". The second person gives a short answer that the first person needs even though actually she/he can give more information about that.

\section{Data 13}

Augustus : Are you currently at your house?

Hazel : Um, no

The next datum is an example of maxim of quantity. It can be seen the meaning of the quantity here. As quantity means only say that for which you have adequate evidence. It can be seen from the answer of the second person "Um, no". The second person gives a short answer that the first person needs even though actually she/he can give more information about that.

\section{Data 14}

Mother : Do you want me to put those in a vase?

Hazel : No, it's okay

The next datum is an example of maxim of quantity. From the example, it can be seen the meaning of the quantity here. As quantity means only say that for which you have adequate evidence. It can be seen from the answer of the second person "No, it's okay". The second person gives a short answer that the first person needs even though actually she/he can give more about that.

\section{Data 15}

Father : So you met Hazel at Support Group

Augustus : Yes, sir.

The next datum is an example of maxim of quantity. It can be seen the meaning of the quantity here. As quantity means only say that for which you have adequate evidence. It can be seen from the answer of the second person "Yes, sir". The second person gives a short answer that the first person needs even though actually she/he can give more about that.

\section{Maxim of Quality}

\section{Data 1}

Hazel : Do you have siblings?

Augustus : Huh?

Hazel : You said that thing about watching kids play

Augustus : Oh yeah, no. I have nephews, from my half- sisters. (Green, 2012 Chpt 2 p.32)

The first datum is example of maxim of quality. It can be seen the meaning of the quality here, provide as much information as required. In this case, the answer of Augustus: "Oh yeah, no. I have nephews, from my half- sisters" related to the quality. The answer from the second person is required to be original and justified and the 
answer must be original can prove that he has no siblings but he has nephews, from his half- sisters.

\section{Data 2}

Hazel : How Old are Julie and Martha?

Augustus : Twenty-eight!" They live in Chicago (Green, 2012 Chpt 2 p.32)

The second datum is example of maxim of quality. From the example it can be seen what the meaning of the quality here, provide as much information as required. In this case, the answer of Augustus: "Twenty-eight!" They live in Chicago" related to the quality. The answer from the second person is required to be original and justified and the answer must be original can prove that Julie and Martha are twenty-eight and they live in Chicago.

\section{Data 3}

Augustus : What is your favorite?

Hazel : Um, My favorite book, by a wide margin, was An Imperial Affliction (Green, 2012 Chpt 2 p.33)

The third datum is example of maxim of quality. From the example it can be seen what the meaning of the quality here, provide as much information as required. In this case, the answer of Hazel: "Um, My favorite book, by a wide margin, was An Imperial Affliction, related to the quality. The answer from the second person is required to be original and justified and the answer must be original can prove that her favorite book was An Imperial Affliction.

\section{Maxim of Relation}

\section{Data 1}

Hazel : Why are you looking at me like that?

Augustus : Because you are beautiful. I enjoy looking at beautiful people, and I decided a while ago not to deny myself the simpler pleasure of existence. (Green, 2012 Chpt 1 p.16)

The first datum is example of maxim of relation. It can be seen what the meaning of the relation here, be relevant. In this case, the answer of the second person: "Because you are beautiful. I enjoy looking at beautiful people, and I decided a while ago not to deny myself the simpler pleasure of existence" related to the relation. The answer from the second person is relevant to the question of first character.

\section{Data 2}

Augustus Mom : You're joining us for dinner, I hope

Hazel : I guess I have to be home by ten. Also I don't, um, eat meat. (Green, 2012 Chpt 2 p.28)

The second datum is example of maxim of relation. From the example it can be seen what the meaning of the relation here, be relevant. In this case, the answer of Hazel: "I guess I have to be home by ten. Also I don't, um, eat meat" related to the relation. The answer from the second person is relevant to the question of first character.

\section{Data 3}


Augustus : What do you read?

Hazel :Everything. From, like, hideous romance to pretentious fiction to poetry. Whatever (Green, 2012 Chpt 2 p.33)

The third datum is example of maxim of relation. It can be seen the meaning of the relation here, be relevant. In this case, the answer of the second person: "Everything. From, like, hideous romance to pretentious fiction to poetry. Whatever." related to the relation. The answer from the second person is relevant to the question of first person.

\section{Data 4}

Mother : What do you want to do on your very special day?

Hazel : Come home from class and set the world record for number of episodes of Top Chef watched consecutively. (Green, 2012 Chpt 3 p.40)

The fourth datum is example of maxim of quality. From the example it can be seen what the meaning of the relation here, be relevant. In this case, the answer of Hazel: "Come home from class and set the world record for number of episodes of Top Chef watched consecutively" related to the relation. The answer from the second person is relevant to the question of first person.

\section{Data 5}

Mother : You don't want to go to a movie with Kaitlyn or Matt or someone? Hazel : Sure, I'll text Kaitlyn and see if she wants to go to the mall or something after school. (Green, 2012 Chpt 3 p.40)

The fifth datum is example of maxim of relation. It can be seen what the meaning of the relation here, be relevant. In this case, the answer of the second person: "Sure, I'll text Kaitlyn and see if she wants to go to the mall or something after school" related to the relation. The answer from the second person is relevant to the question of the first character.

\section{Data 6}

Augustus : Hazel Grace, So have you read it?

Hazel : Well, I haven't finished it. It's six hundred fifty-one pages long and I've had twenty-four hours

The next datum is example of maxim of relation. From the example it can be seen what the meaning of the relation here, be relevant. In this case, the answer of the second person: "Well, I haven't finished it. It's six hundred fifty-one pages long and I've had twenty-four hours" related to the relation. The answer from the second person is relevant to the question of first character.

\section{Data 7}

Hazel : Wanna go to a movie?

Mother :Sure. Anything you've wanted to see?

The next datum is also example of maxim of relation. It can be seen what the meaning of the relation here, be relevant. In this case, the answer of the second person: "Sure. Anything you've been wanting to see?" related to the relation. The answer from the second person is relevant to the question of first character. 


\section{Data 8}

Hazel : Why do they want to get into the school?

Augustus :They want the kids as hostages

The next datum is also example of maxim of relation. From the example it can be seen what the meaning of the relation here, be relevant. In this case, the answer of the second person: "They want the kids as hostages" related to the relation. The answer from the second person is relevant to the question of first character.

\section{Data 9}

Isaac : How can you just break the promise?

Hazel : Sometimes people don't understand the promises they're making when they make them

The next datum is also example of maxim of relation. From the example it can be seen what the meaning of the relation here, be relevant. In this case, the answer of the second person: "Sometimes people don't understand the promises they're making when they make them" related to the relation. The answer from the second person is relevant to the question of first character.

\section{Data 10}

Mother : It's really important to you, yeah?

Hazel : It would be pretty amazing

The next datum is also example of maxim of relation. It can be seen the meaning of the relation here, be relevant. In this case, the answer of the second person: "It would be pretty amazing" related to the relation. The answer from the second person is relevant to the question of first character.

\section{Maxim of Manner}

\section{Data 1}

Mother : Did you just wait outside the entire time?

Hazel :Yes. I brought some paperwork. Anyway, time to face the day, young lady.

The first datum is example of maxim of manner. From the example it can be seen what the meaning of the manner here, avoid obscurity of expression, avoid unnecessary ambiguity, be brief, and be orderly. In this case, the answer of Hazel: "Yes. I brought some paperwork. Anyway, time to face the day, young lady" related to the manner. It shows in the answer that tells the way she waits outside. It is important to explain in good manner so the information will accept clearly.

\section{Data 2}

Hazel : Did you just wait here the entire time?

Mother : No, I picked up the dry cleaning and went to the post office.

The next datum is example of maxim of manner. It can be seen what the meaning of the manner here, avoid obscurity of expression, avoid unnecessary ambiguity, be brief, and be orderly. In this case, the answer of Hazels mother: "No, I picked up the dry cleaning and went to the post office" related to the manner. It shows in the answer that tells the way she waits outside. It is important to explain in good manner so the information will accept clearly. 


\section{Conclusion}

In this research, the writer explains the four maxims in cooperative principle that is the maxim of quantity, the maxim of quality, the maxim of relation, the maxim of manner. The writer also gives thirty data from a novel entitled "The Fault in Our Stars" in this research to make it more clear and easy to understand. The example also has been analyzing by the writer. From all of this, the writer concludes that the cooperative principle is mostly used in the novel. From thirty data that is taken, there are fifteen maxims of quantity, three maxims of quality, ten maxims of relation, and only two maxim of manner. So Cooperative Principle not only used in daily life but it also can we find in novel, movie, drama script, conversation, and another. The writer hopes that this research can be useful for the writer and reader.

\section{References}

Andy, A., \& Ambalegin, A. (2019). Maxims Violation on "Night At the Museum" Movie. Jurnal Basis, 6(2), 215. https://doi.org/10.33884/basisupb.v6i2.1421 Betty J. Birner. (2013). Introduction to Pragmatics (3rd ed.). UK: Wiley-Blackwell. Green, J. (2012). The fault in our stars (Vol. 53). https://doi.org/10.1017/CB09781107415324.004

Grice, P. (1975). Logic and conversation. Logic and Conversation. New York: Academic Press.

Laila, N. A. (2019). Cooperative principles in the 2019 Indonesian Presidential Debate: Grice's maxim analysis. Applied Linguistics Research Journal, 4(1), 1422. https://doi.org/10.14744/alrj.2019.85057

Masruddin, M. (2018). Lessons in Old Man and The Sea. IDEAS: Journal on English Language Teaching and Learning, Linguistics and Literature, 1(1). doi:https://doi.org/10.24256/ideas.v1i1.126

Nurul, A. (2019). Anderson Taxonomy-Based Intensive Test Evaluation Tool for Senior High School. IDEAS: Journal on English Language Teaching and Learning, Linguistics and Literature, 7(1). doi:https://doi.org/10.24256/ideas.v7i1.725

Sapalakkai, O. (2018). Cooperative principle used by Chris Gardner in "The Pursuit of Happyness" movie. K@ta Kita, 6(1), 105-112. https://doi.org/10.9744/katakita.6.1.105-112

Sembiring, W. A., \& Ambalegin, A. (2019). Illocutionary acts on Aladdin movie 2019. Jurnal Basis, 6(2), 279. https://doi.org/10.33884/basisupb.v6i2.1419

Sudaryanto. (2015). Metode dan aneka teknik analisis bahasa. Yogyakarta: Sa. Utami, S. W., Nugraheni, Y., \& Hardiyanti, D. (2017). Gricean maxim an analysis of Beatrice's utterances in Divergent movie. English Language and Literature International Conference (ELLiC), 325-330.

Yule, G. (2005). The study of language (Third). New York: Cambridge University Press, New York. 
Sasmi Saragih, Mhd. Johan

Maxims in Novel "The Fault In Our Stars" By John Green: Pragmatics Approach 